\title{
Influence of Heat-Treatment on Enhancement of Yield Strength and Hardness by Ti-V-Nb Alloying in High-Manganese Austenitic Steel
}

\author{
Zaifeng Zhou ${ }^{\circledR}$, Zhexuan Zhang, Quan Shan *®D, Zulai Li *, Yehua Jiang and Ru Ge \\ School of Materials Science and Engineering, Kunming University of Science and Technology, Kunming 650093, \\ China; shanshuozzf1229@gmail.com (Z.Z.); zhexuanindustries@outlook.com (Z.Z.); \\ jiangyehua@kmust.edu.cn (Y.J.); 18354170573@163.com (R.G.) \\ * Correspondence: quanshan.ms@gmail.com (Q.S.); lizulai@126.com (Z.L.); Tel.: +86-137-0889-4106 (Q.S.); \\ +86-138-8851-6050 (Z.L.)
}

Received: 5 February 2019; Accepted: 28 February 2019; Published: 6 March 2019

\begin{abstract}
To deal with the problem of poor yield strength and hardness in the initial use of high-manganese austenitic steel, we investigated the alloying design, microstructure, precipitates, mechanical properties, and comprehensive strengthening mechanism of high-manganese austenitic steel through two novel heat-treatment processes, namely continuous heating process (CHP) and segmented heat preservation process (SHPP). In this work, austenitic Fe-0.9C-17Mn-0.8Si-2.0 Cr$0.3 \mathrm{Ni}-0.5 \mathrm{Cu}-0.7 \mathrm{Mo}$ steels alloyed with $\mathrm{Ti}, \mathrm{V}$, and $\mathrm{Nb}$ were designed. The grain size of SHPP steels was smaller than that of CHP steels due to the smaller size of precipitates. The results of mechanical experiments showed that the yield strength and impact toughness of SHPP steel were obviously higher than those of CHP steel, but the Brinell hardness of CHP steel was higher than that of SHPP steel. The higher Brinell hardness and poorer impact toughness of CHP steel were mainly due to the larger-sized precipitates. Finally, solid-solution strengthening played the most effective role of increasing the yield and tensile strengths of the two steels.
\end{abstract}

Keywords: Ti-V-Nb alloyed; high-manganese austenitic steel; heat-treatment; micro-scale and nano-scale precipitates; solid-solution strengthening effect

\section{Introduction}

In the past few years, a great deal of studies have been carried out to develop new-generation steels with significantly improved strength-toughness synergy for excellent wear-resistance applications. Meanwhile, with the upsizing of mining and rapid development of the automotive industry, high-manganese austenitic steel has received more attention due to its excellent mechanical properties, as it combines excellent wear-resistance and work-hardening capacity with high ductility and impact toughness [1-3]. ZGMn13Cr2 steel has been widely used for a long time in metallurgy, mining, construction materials, railroading, and power industry as well as the manufacture of cement owing to its high work-hardening capacity and impact toughness under high-load impact and heavy stress [4]. However, this steel is unable to fulfil the requirements of high initial hardness and yield strength under low load impact or in the first stages of use [1]. For instance, semi-autogenous (SAG) mills are now widely used in mining machinery as highly crucial equipment, and the replaceable wear-resistant surface in SAG mills are provided by mill liners, which protect the cylinder against impact abrasion of rolling ore and grinding balls [5]. When ZGMn13Cr steel is used to manufacture SAG mill liners, insufficient initial hardness and yield strength can cause mill liners to experience severe deformation, which will deteriorate the wear-resistance, severely increase the difficulty of mill liner replacement, and increase the loss of material [6], as shown in Figure 1. Therefore, in order to enhance the mechanical 
properties and extend the lifecycle of high-manganese austenitic steel, it is crucial to improve the yield strength and initial hardness.
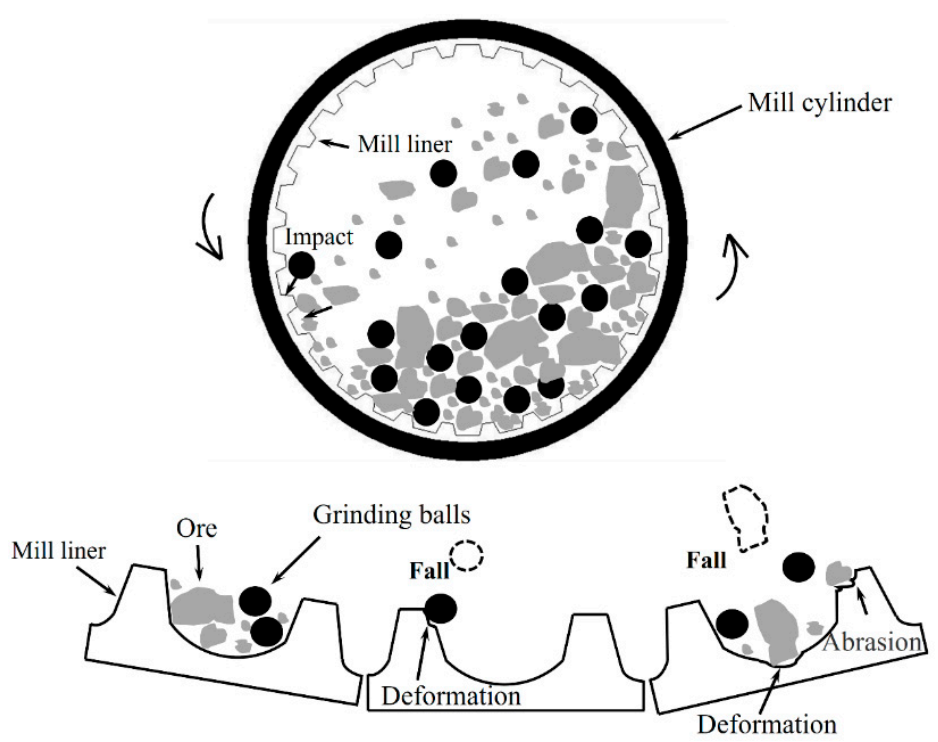

Figure 1. Schematic diagram of abrasion reason of traditional austenitic steel mill liners.

Precipitation strengthening and solid-solution strengthening were usually used to enhance the hardness and yield strength of high-manganese austenitic steel by addition of alloying elements and a proper heat treatment process $[1,7,8]$. In this work, $\mathrm{Ti}, \mathrm{Nb}$, and $\mathrm{V}$ were introduced into steel because they could combine with $\mathrm{C}$ or $\mathrm{N}$ to form precipitates of carbides, nitrides, and carbonitrides [7]. These fine precipitates can significantly improve the yield strength of steels due to the grain size refinement by pinning the austenite grain boundaries, and increase the precipitation hardening by hindering dislocation motion $[9,10]$; some larger precipitates can enhance initial hardness and wear-resistance by enhancing structure hardening [11]. Scott et al. [12] reported on the influence of strengthening by precipitates of $\mathrm{Ti}, \mathrm{V}$, and $\mathrm{Nb}$ on different-composition high-manganese austenitic steels hot and cold strips, and experimental results revealed that $\mathrm{Ti}$ provides the highest precipitation strengthening effect in cold strips, and the strengthening effect of $\mathrm{V}$ was lower than Ti but higher than $\mathrm{Nb}$. It is well known that precipitation strengthening and solid-solution strengthening of high-manganese steels depend also on the heat treatment applied [13,14]. Nevertheless, fewer studies have been carried out to investigate the heat treatment process of Ti-V-Nb alloyed high-manganese steels; and there is also scarce literature examining the effect of heat treatment process on the relationship between microstructure and mechanical properties of Ti- $\mathrm{V}-\mathrm{Nb}$ alloying high manganese steel. Therefore, this constitutes the originality and aims of the current study.

High-manganese steel has different types of non-metallic inclusions of Mn, which form during casting or melting. The corrosion pits nucleate preferentially on the non-metallic inclusions when high manganese steel is used in acidic, alkaline, or chloride solutions, which results in poor corrosion resistance of the steel. Because $\mathrm{Cr}-\mathrm{Ni}$ austenitic stainless steels have excellent corrosion resistance, $\mathrm{Cr}$ and Ni were added to experimental steel to improve its corrosion resistance [15]. Samek et al. [2] reported that Fe-0.8C-16Mn steels had a typical stacking fault energy ranging from 10 to $60 \mathrm{~mJ} / \mathrm{m}^{2}$, a high tensile strength of $1100 \mathrm{MPa}$, and a remarkably high tensile total elongation (about 100\%) by the TRIP/TWIP effect. Therefore, the tested steel in the current work was austenitic manganese Fe-0.9C-17Mn steel.

In the current work, austenitic manganese Fe-0.9C-17Mn steel alloyed with $\mathrm{Ti}, \mathrm{V}$, and $\mathrm{Nb}$ was designed, and two novel heat-treatment processes, namely continuous heating (CHP) and segmented heat preservation (SHPP), were carried out after casting. The main focus of this work was on the microstructure, precipitation behavior of precipitates, and mechanical properties of steels. A room 
temperature tensile test, impact toughness test, Brinell hardness test, and microscopy techniques were used to reveal the effect of the nature of Ti- $\mathrm{V}-\mathrm{Nb}$ precipitates on the mechanical properties of austenitic manganese steel. Finally, the strengthening mechanism of tested steels was investigated.

\section{Experimental Procedures}

\subsection{Materials and Methods}

In this work, the raw materials of alloy austenitic steel are provided in Table 1. The alloying design of Fe-17Mn-0.9C aimed to obtain the appropriate stacking fault energy and stable austenite phase zone [2,16,17]. The addition of Mo was used to refine precipitate particles [18]. $\mathrm{Si}$, Ni, and $\mathrm{Cr}$ were used to improve corrosion resistance [19]. Moreover, Ni could significantly enhance the impact toughness of high-manganese steel [8]. Figure 2a,b shows two different heat-treatments of the tested steel. The phase equilibrium diagrams were calculated using ProCAST software (2014.5, ESI Corporation, Paris, France), as shown in Figure 3. The precipitation temperature of $M(C, N)$ was approximately $1317^{\circ} \mathrm{C}$ in steel, the $\mathrm{M}_{7} \mathrm{C}_{3}$ and $\mathrm{M}_{23} \mathrm{C}_{6}$ precipitation temperature were both below $100{ }^{\circ} \mathrm{C} . \mathrm{M}(\mathrm{C}, \mathrm{N})$ precipitated at $1317^{\circ} \mathrm{C}$ was mainly composed of $\operatorname{Ti}(\mathrm{C}, \mathrm{N})$, which could refine austenite grain by pinning grain boundaries. On the one hand, in order not to significantly reduce the toughness and prevent abnormal grain coarsening, the temperature was set at $1070{ }^{\circ} \mathrm{C}$ [20]. On the other hand, due to the large size of the mill liners and the poor thermal conductivity of austenitic steel [21], in order to avoid the occurrence of hot cracks, a process of segmented heat preservation heating was designed. During the isothermal holding process at $450{ }^{\circ} \mathrm{C}$ and $650{ }^{\circ} \mathrm{C}$, the austenite stability was reduced, resulting in the formation of M7C3 and M23C6 carbides, as shown in Figure 3. The experimental steels were prepared by industrial induction melting under atmospheric conditions using pure iron, scrap steel, ferromanganese, ferrosilicon, pure nickel, ferrochrome, ferrotitanium, ferrocolumbium, ferrovanadium, ferromolybdenum, and pure cupper. The forming technology of the tested steel was sand casting. After smelting, the steel was cast into mill liners, as shown in Figure 4e. After the two different heat-treatment processes, $300 \times 150 \times 150 \mathrm{~mm}^{3}$ ingots were cut from each of the two mill liners.

Table 1. Chemical compositions of experimental steel (wt.\%).

\begin{tabular}{cccccccccccc}
\hline $\mathbf{C}$ & $\mathbf{S i}$ & $\mathbf{M n}$ & $\mathbf{C r}$ & $\mathbf{T i}$ & $\mathbf{V}$ & $\mathbf{N b}$ & $\mathbf{C u}$ & $\mathbf{M o}$ & $\mathbf{N i}$ & $\mathbf{P}$ & $\mathbf{S}$ \\
\hline 0.89 & 0.81 & 16.98 & 2.0 & 0.11 & 0.43 & 0.25 & 0.49 & 0.73 & 0.29 & 0.01 & 0.02 \\
\hline
\end{tabular}

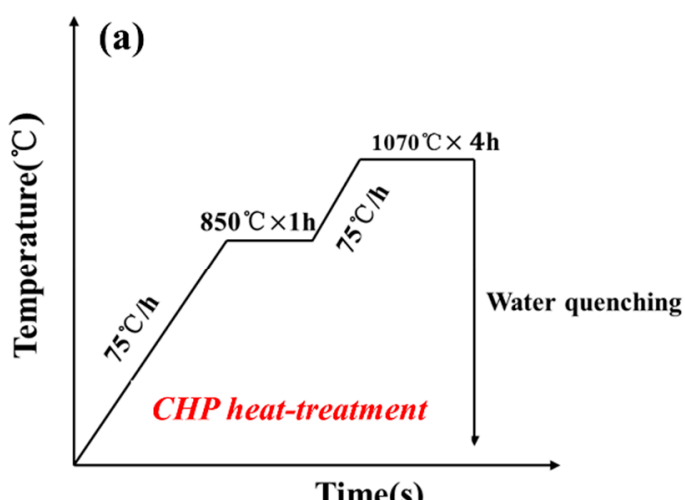

Time(s)

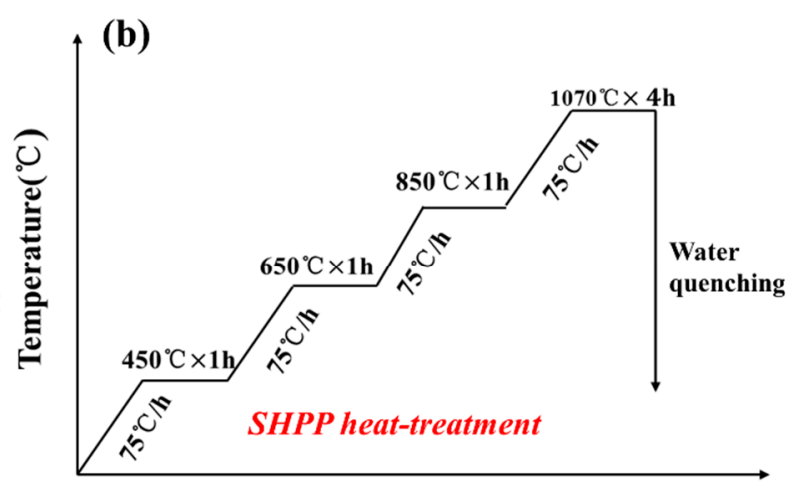

Time(s)

Figure 2. Heat-treatment curve of continuous heating process (CHP) (a) and segmented heat preservation process (SHPP) (b) of steel. 


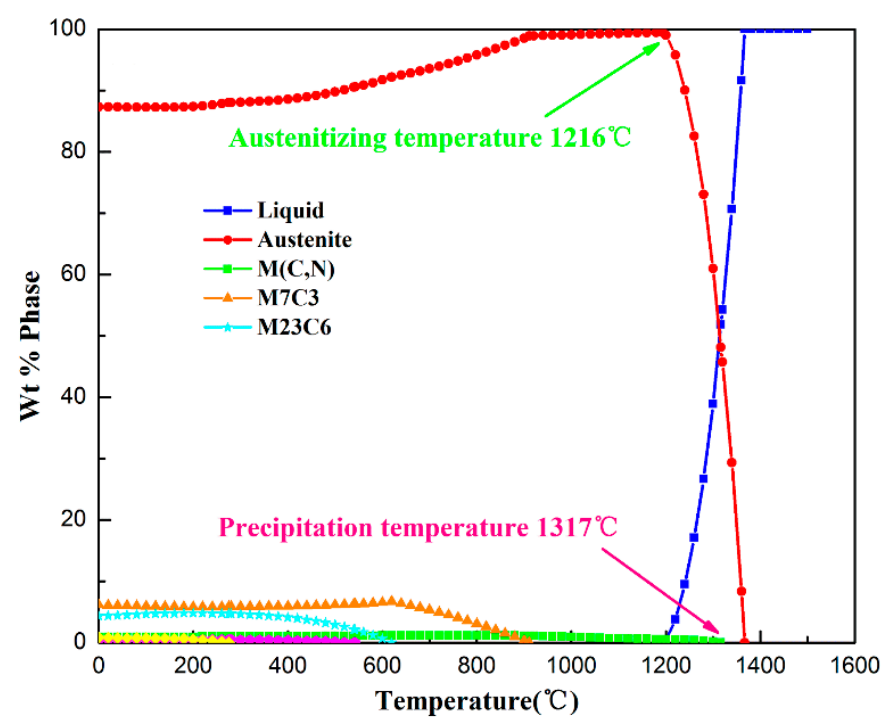

Figure 3. Phase equilibrium diagram of experimental steel.

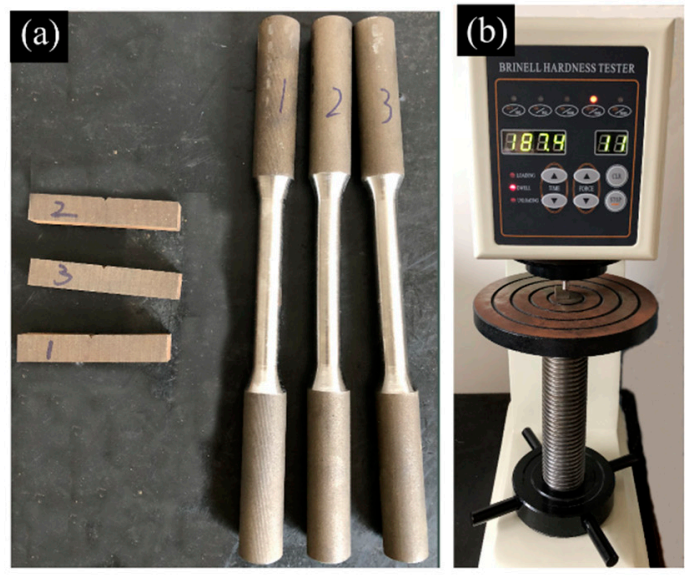

(c)
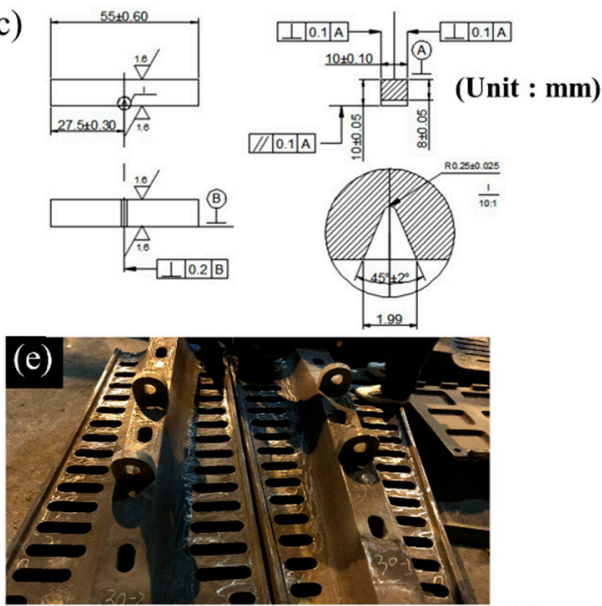

(d)

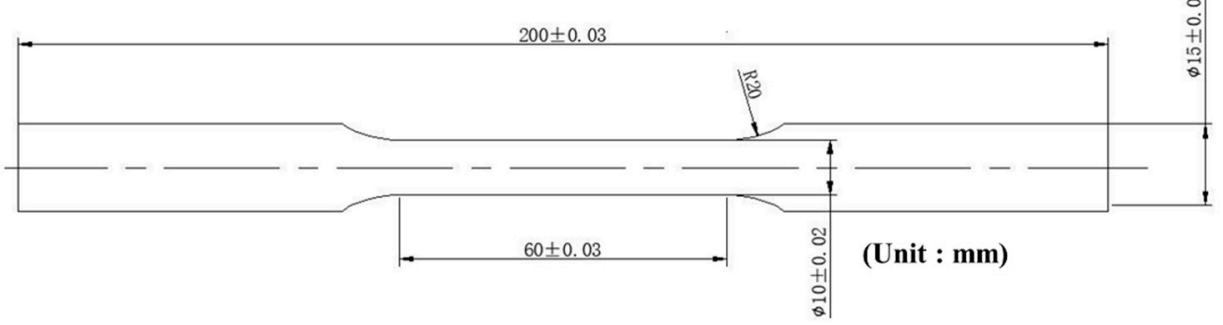

Figure 4. (a) Physical picture of tensile specimen and impact toughness test specimen. (b) Schematic diagram of hardness experiment. Drawing of impact specimen (c) and tensile specimen (d). (e) The physical picture of casting mill liners.

\subsection{Characterization}

As shown in Figure 4c,d, the Charpy impact-test samples with V-notch and tensile-test samples with $\Phi 15 \mathrm{~mm}$ and $60 \mathrm{~mm}$ gauge length were machined from the ingots. Standard tensile tests were performed using a WDW-600C tensile test machine (Shanghai hualong testing instrument Co. Ltd, Shanghai, China) at room-temperature, and specimens for the tensile test were prepared according to the GB/T 228.1-2010 standard. Impact toughness was measured on a JB-30B impact tester (Wu zhong material testing machine Co. Ltd, Yinchuan, China) at room-temperature. The Brinell hardness specimens of $15 \times 15 \times 10 \mathrm{~mm}^{3}$ were machined from the ingots. Brinell hardness was measured on 
a HBE-3000A electronic Brinell hardness tester (Shanghai guangmi instrument Co. Ltd, Shanghai, China), as shown in Figure $4 b$.

Observation of microstructures and precipitates was performed using a NOVA NANOSEM 450 field emission scanning electron microscope (FESEM) (FEI Corporation, Hillsboro, OR, USA). For EBSD detections, the specimens were first mechanically polished and then ion-etched with Leica RES101 (Leica Co., Wetzlar, Germany), and EBSD observation was conducted on a Hitachi S-3400N SEM (Hitachi Ltd., Tokyo, Japan) equipped with a HKL-EBSD system. The phase constitution was analyzed with a X'Pert Pro X-ray diffraction system (target: Co, scan rate: $6^{\circ} \mathrm{min}^{-1}$, and scan step size: $0.02^{\circ}$; PANalytical B.V., Almelo, The Netherlands). The fracture morphology of tensile-test specimens and microstructure of cast high-manganese steel were analyzed by using a ZEISS EVO18 scanning electron microscope (SEM) (ZEISS Co. Ltd, Oberkochen, Germany). The particle size of precipitates was counted using Image-pro plus software (6.0, Media Cybernetics Inc., Rockville, MD, USA).

\section{Results and Discussion}

\subsection{Mechanical Properties}

The mechanical properties of the tested samples are provided in Table 2. Each datum was obtained from three specimens, as shown in Figure 4a. The yield strength and tensile strength of the CHP steel were $433 \mathrm{MPa}$ and $595 \mathrm{MPa}$, respectively, and those of the SHPP steel were $501 \mathrm{MPa}$ and 655 $\mathrm{MPa}$, respectively. Compared with the CHP steel, the yield strength and tensile strength of the SHPP steel increased significantly. The tensile strength of the CHP steel was about $60 \mathrm{MPa}$ lower than that of the SHPP steel, and the yield strength was lower approximately $68 \mathrm{MPa}$. Besides having higher yield strength and tensile strength, the SHPP steel also had an excellent impact energy and tensile elongation. The impact energy of the SHPP steel was $28.3 \mathrm{~J}$ higher than that of the CHP steel, and the tensile elongation increased $2 \%$, while the Brinell hardness was lower than that of CHP steel. It was found that the formation of $\mathrm{Ti}-\mathrm{V}-\mathrm{Nb}$ precipitates and the refinement of grain size were the main reasons affecting the mechanical properties, and more details will be discussed later.

Table 2. Mechanical properties of experimental steels.

\begin{tabular}{cccccc}
\hline $\begin{array}{c}\text { Heat } \\
\text { Treatment }\end{array}$ & $\begin{array}{c}\text { Charpy } \\
\text { Impact/J }\end{array}$ & Hardness/HBW & $\begin{array}{c}\text { Yield } \\
\text { Strength/MPa }\end{array}$ & $\begin{array}{c}\text { Tensile } \\
\text { Strength/MPa }\end{array}$ & $\begin{array}{c}\text { Tensile } \\
\text { Elongation/\% }\end{array}$ \\
\hline CHP & 20.7 & 252 & 433 & 595 & 9.4 \\
SHPP & 49 & 242 & 501 & 655 & 11.4 \\
\hline
\end{tabular}

The engineering stress-strain curves during the two heat-treatment processes of specimens are shown in Figure 5. Both steels showed continuous yielding, and it was also observed that the slope of the curve of SHPP steel was higher than that of CHP steel; thus, the SHPP steel exhibited a higher strain-hardening rate. This was due to the difference of precipitates and solid-solution strengthening, and more details will be provided later. The difference between the elongation of the two steels was not obvious. When the strain reached a maximum value, the samples fractured rapidly after necking. The coarse Ti-Nb-V particle was the direct cause for the steel rapidly fracturing [22].

The room-temperature tensile specimen fracture morphologies of CHP and SHPP steels are shown in Figure 6. Both steel fracture morphologies were typical ductile fracture models. A great amount of microcracks existed in the CHP steel fracture (marked by red arrows); at the same time, there were many micron-scale particles (marked by purple circles) near the microcracks, which is shown in Figure 6a,b. Figure 6c shows the large and shallow dimples of the CHP steel fractograph (marked by blue arrows). Compared with the CHP steel fracture morphology, SHPP steel had more small and deep dimples at the fracture; meanwhile, the dimples were more evenly distributed, which is shown in Figure 6e. Figure 6d shows the precipitate particles of the SHPP steel fracture, with the smaller particles being distributed in deep and small dimples. The number of microcracks in the SHPP steel 
fracture was lower than in the CHP steel fracture, as shown in Figure 6f. During the tensile process, when the stress on the specimens exceeds the precipitation particle deformation resistance, microcracks would occur in the steel. As the loading process progresses, the microcracks would be elongated or deformed, resulting in specimen fracture. The larger size precipitates in steel tend to become stress concentration points, which will reduce the grain boundary strength when distributed at the grain boundary, leading to the generation of microcracks more easily [22,23]. The coarse precipitates of the CHP steel deteriorated the toughness of the steel; during the tensile process, a number of microcracks rapidly formed around the coarse particles, which accelerated the fracture of the specimen, resulting in a decrease in tensile strength and elongation of CHP steel. The results showed that the precipitates in SHPP steel were smaller; therefore, the use of Ti-V-Nb alloying with SHPP heat-treatment could enhance the yield strength and maintain an excellent toughness and elongation.

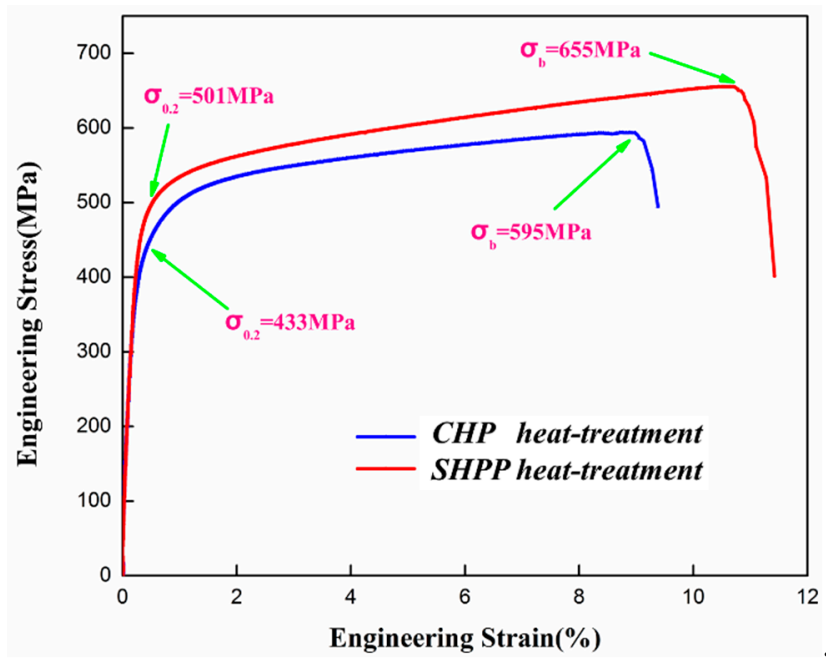

Figure 5. Engineering stress-strain curve of CHP steel (blue curve) and SHPP steel (red curve).

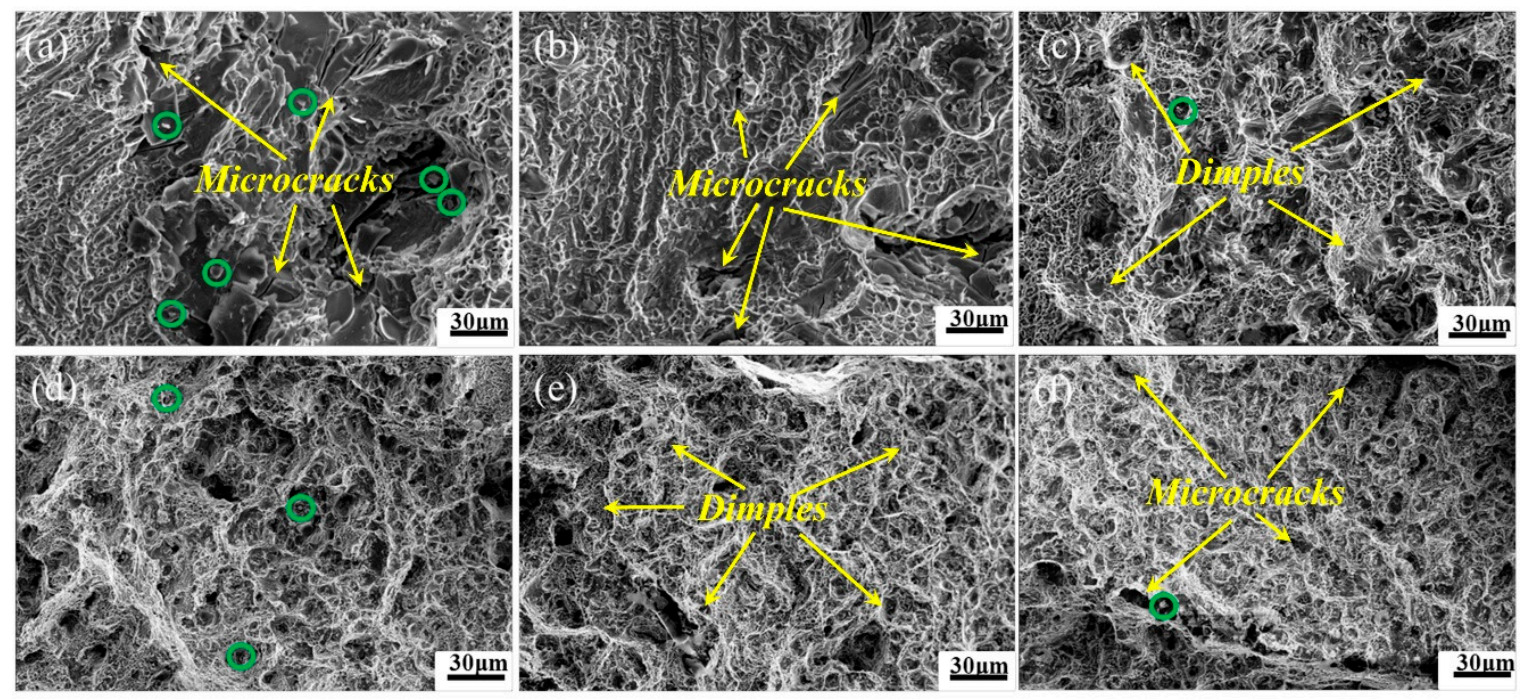

Figure 6. Room-temperature tensile fracture morphologies of CHP steel $(\mathbf{a}-\mathbf{c})$ and SHPP steel $(\mathbf{d}-\mathbf{f})$.

\subsection{X-Ray Diffraction Phase Analysis}

Figure 7 shows the X-ray diffraction (XRD) pattern of CHP and SHPP steels. From the XRD results, only the diffraction peaks of austenite were found in the steels with two heat-treatment processes, but there were no diffraction peaks of martensite and precipitates. This was due to the high content of $\mathrm{Mn}$ and $\mathrm{C}$ in the steel to stabilize the austenite phase region [16,24], and the precipitates accounted 
only for a small part of the volume fraction in both steels. Additionally, it was also found that the diffraction peak intensities of both steels was different. This may be related to the preferred grain orientation and texture of both steels after solid-solution treatment processes, resulting in a change in the number of crystal faces involved in diffraction, so the diffraction peak intensities of both steels changed. This will be further discussed later in combination with the EBSD experimental results.

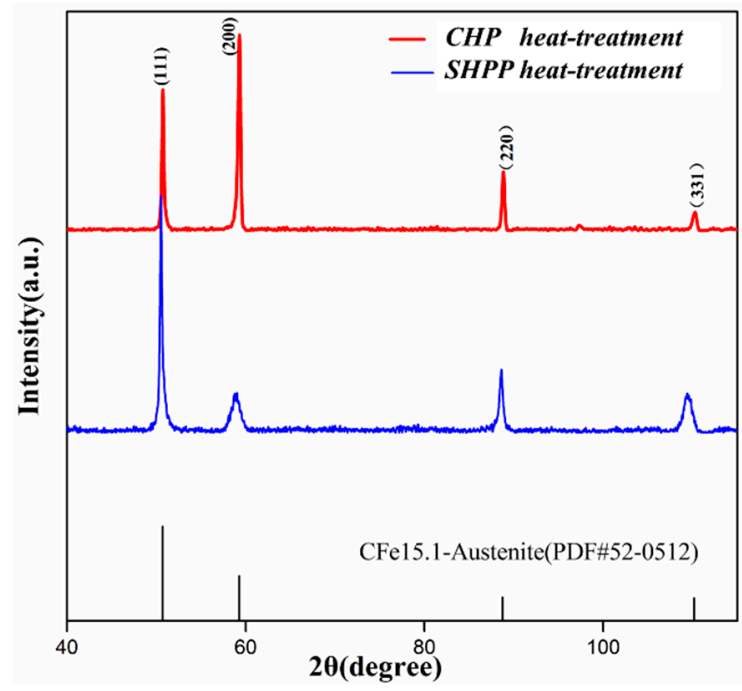

Figure 7. Phase analysis by X-ray diffraction (XRD) pattern of CHP steel (red curve) and SHPP steel (blue curve).

\subsection{Microstructural Analysis}

Figure 8 shows the SEM microstructure of cast high-manganese steel. According to Figure 8a, some smaller micron-sized precipitates existed at the austenite boundary of cast high manganese steel. Figure $8 \mathrm{~d}$ shows the energy spectrum analysis of these smaller micron-sized precipitates, which mainly contain $\mathrm{Ti}, \mathrm{V}, \mathrm{Nb}, \mathrm{Cr}, \mathrm{Mn}$, and other alloying elements. It can be seen from Figure $8 \mathrm{~b}, \mathrm{c}$ that there were many large-size precipitate particles in cast high-manganese steel; according to Figure 8e, the energy spectrum analysis, these large precipitates also contain a variety of alloying elements. Through SEM observation of cast high manganese steel, it was found that precipitates of $\mathrm{Ti}, \mathrm{V}, \mathrm{Nb}$, and other alloying elements largely precipitated in the microstructure of cast high-manganese steel. These large-size precipitates in cast high manganese steel would seriously deteriorate the mechanical properties of high-manganese steel. Therefore, it was necessary to dissolve part of precipitates into steel through a heat treatment process to improve the mechanical properties of high-manganese steel.

Figure 9a shows the size distribution of austenite grain in cast high-manganese steel: a grain size in the range of 180-220 $\mu \mathrm{m}$ was the most frequent and the average grain size was $193.22 \mu \mathrm{m}$. Figure $9 \mathrm{~b}$ shows the size distribution of precipitates in cast high-manganese steel. The largest amount of precipitates was distributed within the size range of $5-15 \mu \mathrm{m}$ and the average grain size of precipitates was $12.7 \mu \mathrm{m}$.

Figure 10 shows the microstructure of $\mathrm{CHP}$ and SHPP steels. Ti-V-Nb precipitates were observed in both steels; more and larger-size precipitates existed in the CHP steel (marked by yellow circles), which is shown in Figure 10b. It was found that the size of precipitates of both steels significantly decreased after the heat treatment processes, which indicated that part of the precipitates dissolved into the steels during the heat treatment process. Meanwhile, the SHPP caused more precipitates to dissolve into the steel compared with CHP, thus making the precipitate size of SHPP steel lower than that of CHP steel. In the EBSD orientation decomposition image map (Figure 10a) of CHP and SHPP steels, it is clear that the grain size of CHP steel was larger than that of SHPP steel: the grain size of CHP steel was measured to be $272.46 \mu \mathrm{m}$, and that of SHPP steel was $241.3 \mu \mathrm{m}$, as shown in Figure 10c. This indicated that the austenite grain had grown up after the heat-treatment process; meanwhile, the grain size of CHP steel was slightly larger than that of SHPP steel. The reason for 
this phenomenon was that the SHPP added isothermal processes at $450{ }^{\circ} \mathrm{C}$ and $650{ }^{\circ} \mathrm{C}$ compared with CHP. Xu et al. [23] reported that austenite manganese steel tempering below $600{ }^{\circ} \mathrm{C}$ would decrease the stability of austenite and form some carbide precipitates. According to the equilibrium thermodynamic phase diagram in Figure 3, the austenite stability of SHPP steel would decrease during the isothermal processes at $450{ }^{\circ} \mathrm{C}$ and $650{ }^{\circ} \mathrm{C}$, resulting in a small amount of austenite decarburization, forming some M23C6 and M7C3 carbides on the austenite grain boundaries. During the isothermal processes at $850^{\circ} \mathrm{C}$ and $1070{ }^{\circ} \mathrm{C}$, new austenite grain first nucleated and grew at the interface between austenite and carbide. This could play a role in refining the austenite grain. Meanwhile, no obvious crystal preferential orientation was found in either of the steels. This indicated that there was no direct relation between the diffraction peak intensities and texture; the difference of peak intensities may be related to the structure, multiplicity, and absorption factors of the specimens due to the XRD experimental specimens being made into lumps. The total elongation of both investigated steel grades was particularly low. This also indicated that the two types of steel had poor ductility and no significant TRIP/TWIP effect was found [2]. The reasons for this may be as follows. Firstly, large amounts of coarsen carbide particles existed in both steels, stress tend to build up around them resulted in the formation of the microcracks; secondly, both steels were directly formed by cast, and had a large grain size (both over $200 \mu \mathrm{m}$ ), which would significantly deteriorate the elongation; finally, casting defects in experimental steels was also one of the important factors that caused the decrease in elongation.
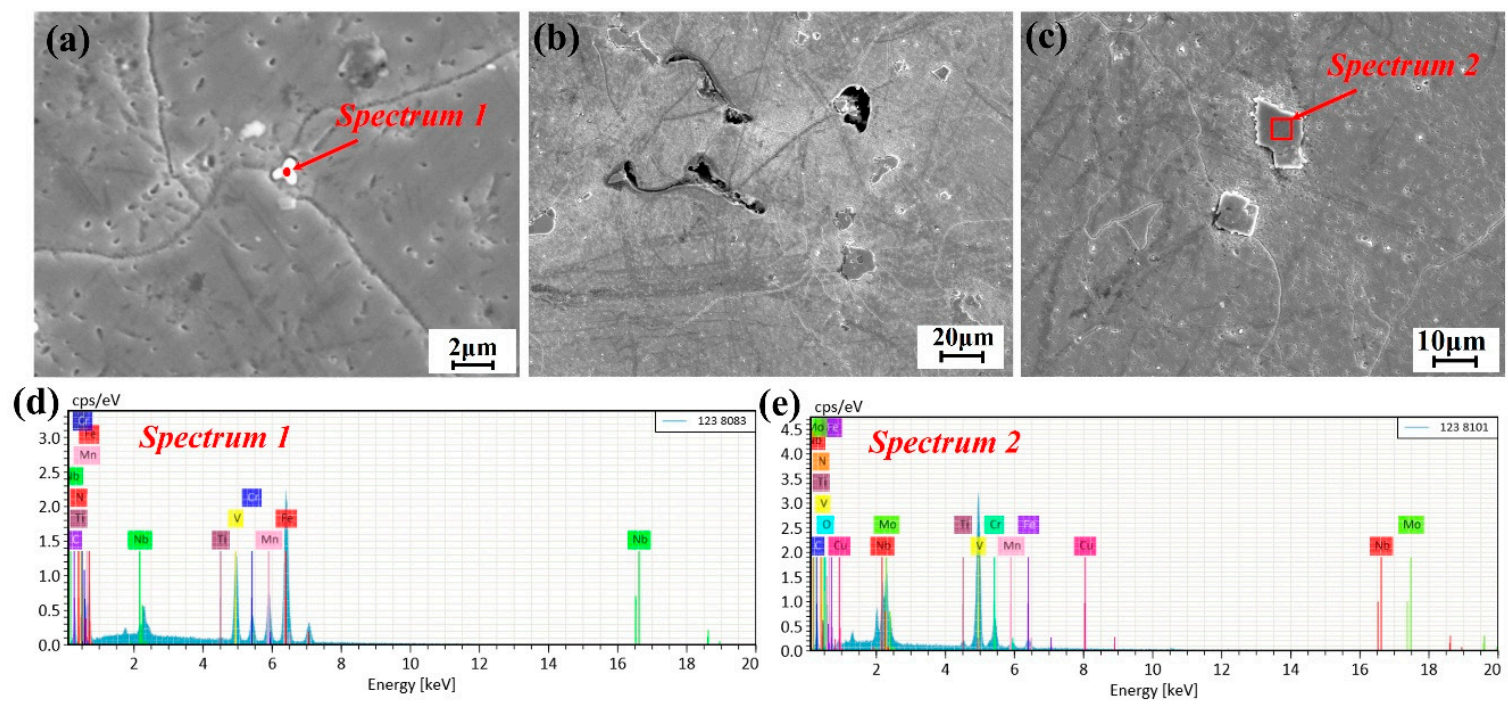

Figure 8. Scanning electron microscope (SEM) microstructure $(\mathbf{a}-\mathbf{c})$ of cast high-manganese steel and energy spectrum analysis $(\mathbf{d}, \mathbf{e})$ of precipitates in cast high-manganese steel.
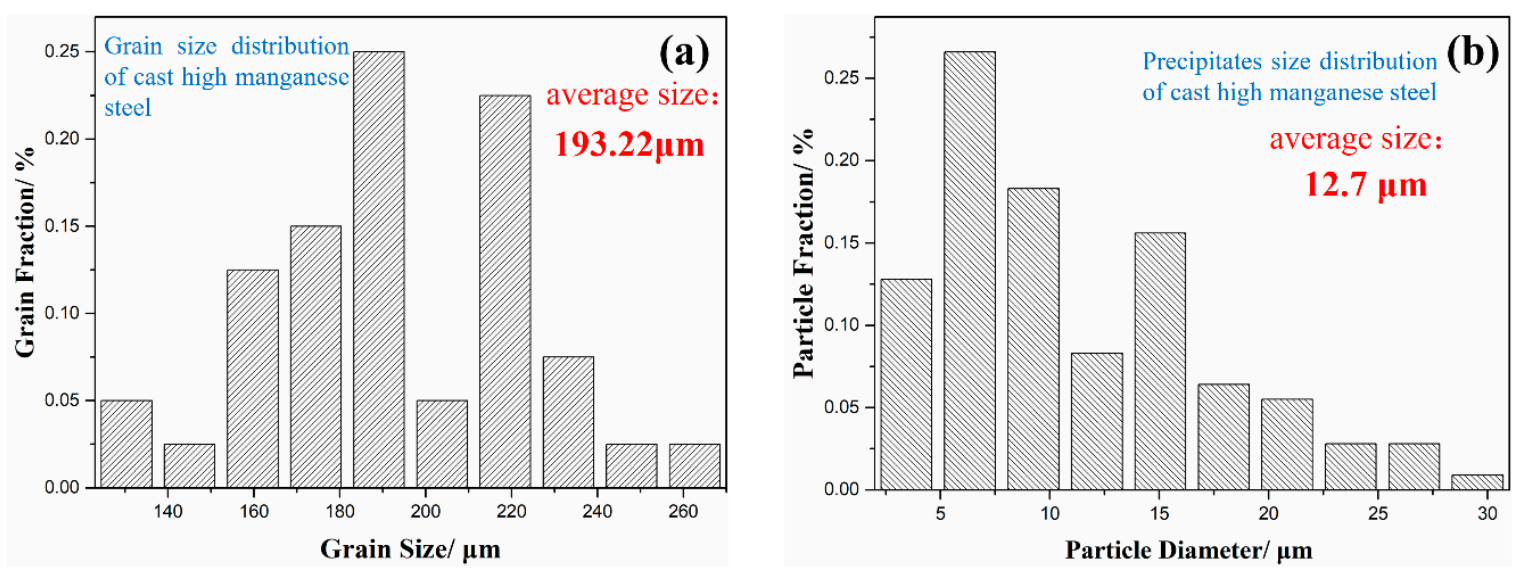

Figure 9. Size distributions of austenite grain (a) and precipitates (b) in cast high-manganese steel. 

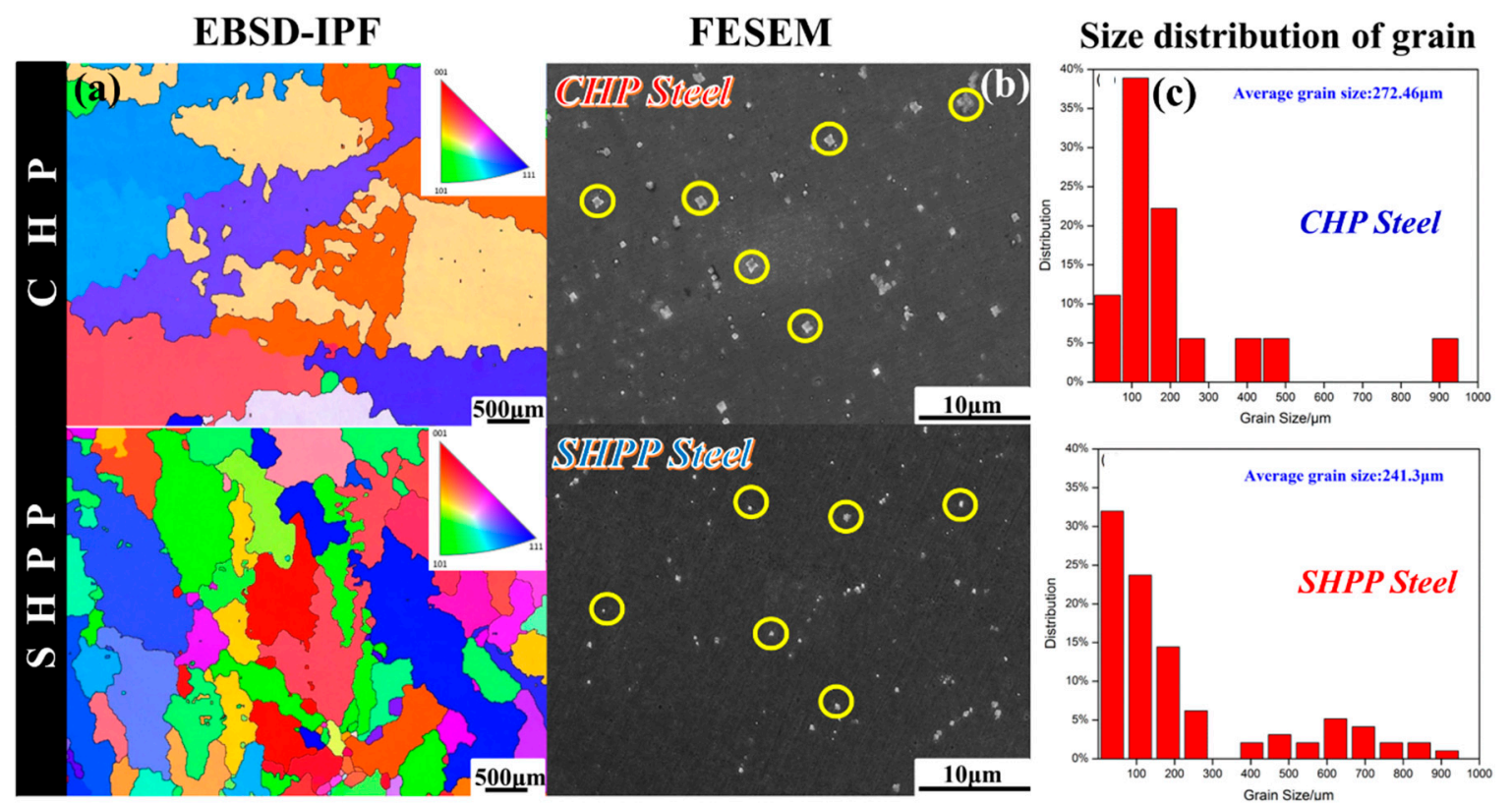

Figure 10. Grain size analysis of CHP and SHPP steel by orientation decomposition image map (a); FESEM micrographs of distribution and quantity of precipitates in both steels (b); size distribution of austenite grain in both steels (c).

Figure 11a shows the distribution, size, and shape of the precipitates in CHP steel. There were large numbers of coarse precipitates unevenly distributed in the CHP steel. The shape of the precipitates was mostly irregular square and elliptical, and had a continuous chain distribution at the austenite grain boundary, resulting in poor toughness of the CHP steel during the Charpy-impact test. These continuous chain precipitates would decrease the grain boundary strength, and the microcracks would be first produced around these particles [22,25].

Figure $11 \mathrm{~b}, \mathrm{c}$ show the cladding structure of the micron-scale precipitates in the CHP steel. The core of precipitate was mainly composed of $\mathrm{TiC}$, and the outer was wrapped with $\mathrm{NbC}$ and a small amount of VC. According to Yong [24], TiC has a relatively low solid solubility product, which can be precipitated at a relatively high temperature; the solid solubility product of $\mathrm{NbC}$ is higher than $\mathrm{TiC}$, resulting its precipitation temperature range being lower than $\mathrm{TiC}$; $\mathrm{VC}$ has the largest solid solubility product, which mainly exists in the solid solution state at high temperature, so the precipitation temperature range of VC is relatively low. Meanwhile, when the crystal structure and lattice parameters of several precipitates are similar, the cladding structure of the precipitates can be formed by mutual dissolution. Therefore, the precipitates of $\mathrm{TiC}$ could act as the nucleation core for the subsequent precipitation of $\mathrm{NbC}$ and $\mathrm{VC}$, eventually producing the large-sized precipitates of this cladding structure.

It is shown in Figure 11d that some small square-shaped precipitates were present in the CHP steel. These small-sized precipitates were confirmed to be VC according to energy spectrum analysis (as shown in Figure 11 (bottom)), which will be discussed later.

Figure 12a shows the precipitates in SHPP steel, which were relatively uniform in distribution and smaller in size compared to the CHP steel. Due to the discontinuous distribution of the precipitates at the grain boundaries, the toughness was significantly better than that of the CHP steel. Figure 12b shows the morphology of the precipitates in SHPP steel below $100 \mathrm{~nm}$, and their shape is spherical. According to energy spectrum analysis, these submicron-scale precipitates (marked by red arrows) of the SHPP steel were VC, as shown in Figure 12 (bottom). Figure 12c shows the size distribution of the precipitates in SHPP steel. Figure $12 \mathrm{~d}$ shows the size distribution of the precipitates in CHP steel; at the same time, the average size of the precipitated particles were $5.19 \mu \mathrm{m}$ and $7.14 \mu \mathrm{m}$. It was found that the number of precipitates below $2.5 \mu \mathrm{m}$ in the SHPP steel was 
obviously higher than in CHP steel, and the CHP steel contained more precipitates above $5 \mu \mathrm{m}$. Due to the precipitation temperature range of the VC being relatively low [24], when the SHPP steel was isothermal at 450 and $650{ }^{\circ} \mathrm{C}$, a part of VC precipitated. The SHPP steel had a higher degree of supercooling because of the lower isothermal temperature, which increased the phase transformation driving force of VC precipitates, and the VC was randomly precipitated in austenite grain [26]. Meanwhile, due to the slow diffusion of alloying elements, the VC precipitates would not show coarsening [27]. Because the CHP steel had no isothermal processes at $450{ }^{\circ} \mathrm{C}$ and $650{ }^{\circ} \mathrm{C}$, $\mathrm{V}$ precipitated together with $\mathrm{Ti}$ and $\mathrm{Nb}$ in isothermal processes at $850^{\circ} \mathrm{C}$ and $1070{ }^{\circ} \mathrm{C}$ [24]. Therefore, a part of $\mathrm{VC}$ was wrapped on the precipitates of $\mathrm{TiC}$ and $\mathrm{NbC}$, reducing the volume fraction of the single VC precipitated particles.

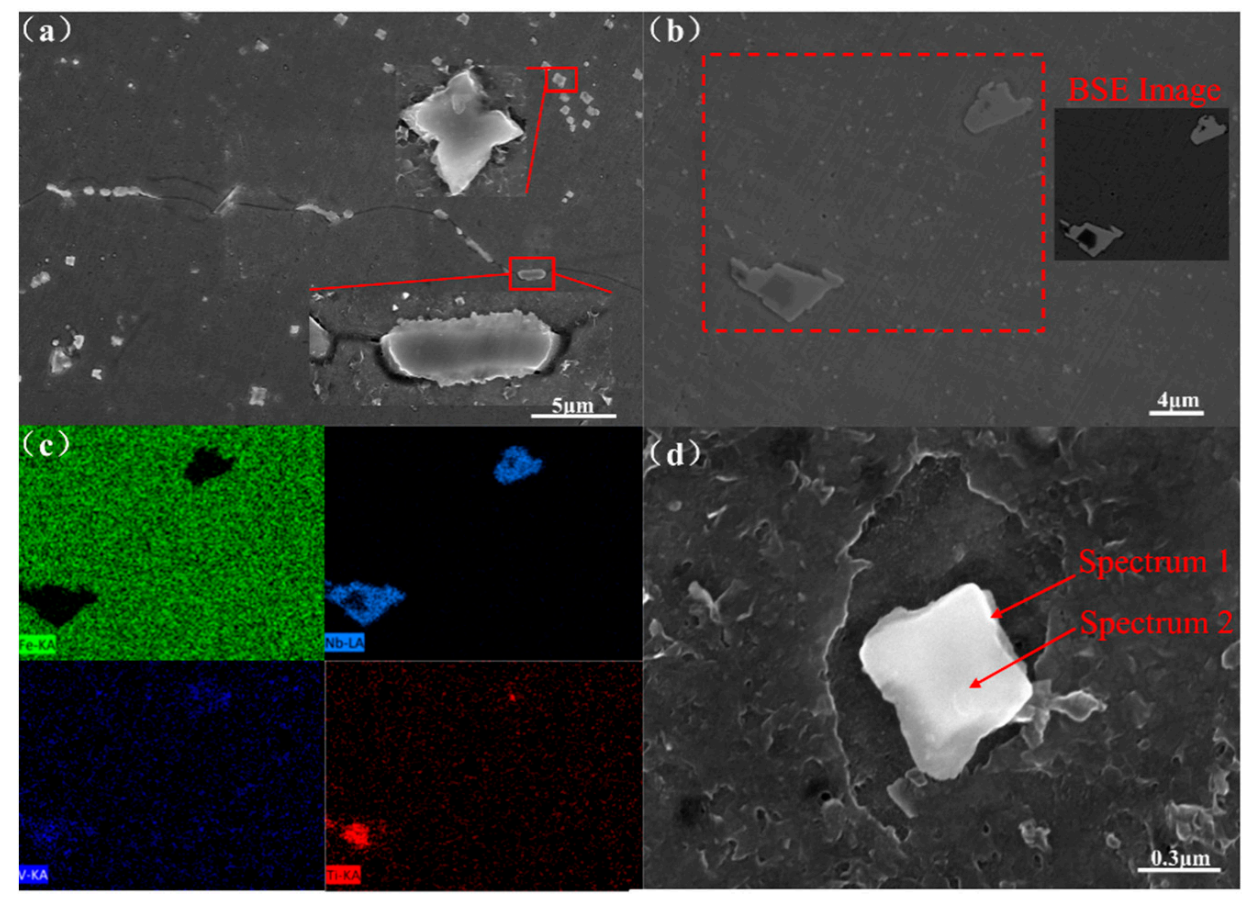

\begin{tabular}{|c|c|c|c|}
\hline Spectrum 1 & $\mathbf{W t} \%$ & Spectrum 2 & $\mathbf{W t} \%$ \\
\hline Fe & 62.8 & Fe & 23.8 \\
\hline V & 13.8 & V & 47.6 \\
\hline C & 9.2 & $\mathrm{C}$ & 18.3 \\
\hline Mn & 13.0 & $\mathrm{Mn}$ & 6.5 \\
\hline
\end{tabular}

Figure 11. Field emission scanning electron microscope (FESEM) micrographs (a,b) and energy spectrum analysis (c) of micron-scale precipitates in CHP steel. FESEM micrographs (d) and energy spectrum analysis (bottom) of submicron-scale precipitates in CHP steel.

According to the color metallography analysis, the volume fraction and average size of the precipitates in CHP steel were larger than in SHPP steel. The larger-sized hard particles in CHP steel resulted in higher surface hardness, which also improved the wear-resistance [28]. 

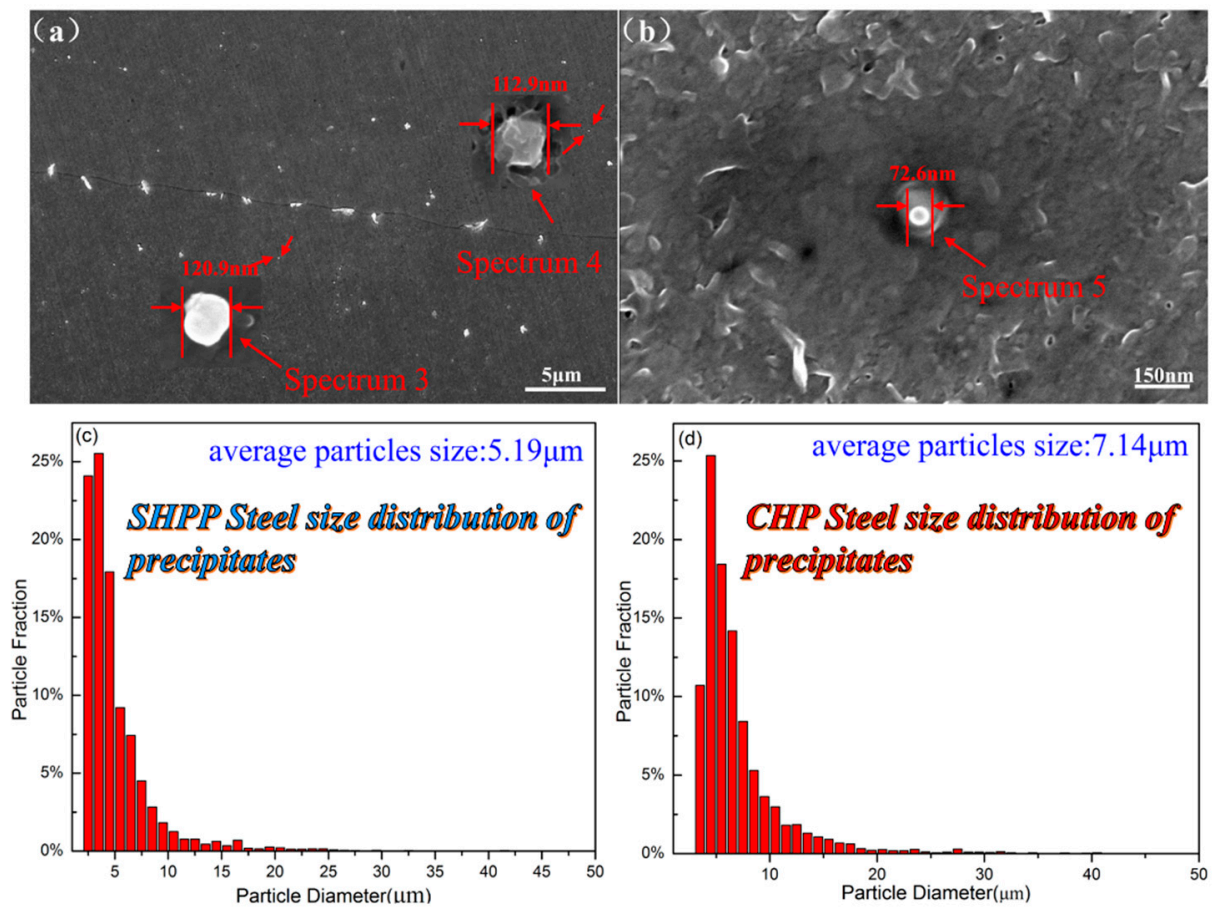

\begin{tabular}{|c|c|}
\hline Spectrum 3 & $\mathbf{W t} \%$ \\
\hline Fe & 45.1 \\
\hline V & 20.4 \\
\hline C & 19.3 \\
\hline Mn & 8.9 \\
\hline
\end{tabular}

\begin{tabular}{|c|c|}
\hline Spectrum 4 & Wt $\%$ \\
\hline Fe & 27.7 \\
\hline V & 18.4 \\
\hline C & 44.1 \\
\hline $\mathrm{Mn}$ & 6.3 \\
\hline
\end{tabular}

\begin{tabular}{|c|c|}
\hline Spectrum 5 & Wt $\%$ \\
\hline $\mathrm{Fe}$ & 35.5 \\
\hline $\mathrm{V}$ & 18.1 \\
\hline $\mathrm{C}$ & 28.6 \\
\hline $\mathrm{Mn}$ & 9.5 \\
\hline
\end{tabular}

Figure 12. (a) FESEM micrographs of the distribution of submicron-scale precipitates in SHPP steel. (b) FESEM micrographs of the nano-scale precipitates in SHPP steels. Precipitate particle size distribution of SHPP steel (c) and CHP steel (d). Energy spectrum analysis (bottom of the picture) of precipitates (marked by red arrows) in (a) and (b) FESEM micrographs.

\subsection{Strengthening Mechanism}

A large number of Ti-V-Nb precipitates were found in both steels observed by FESEM. Therefore, it was significant to discuss the influence of precipitates on the yield strength. Furthermore, and it was necessary to identify the most effective strengthening mechanism for improving the yield strength.

Various strengthening mechanisms synergistically facilitated the yield strength and tensile strength of both steels, such as precipitation strengthening, solid-solution, and grain-boundary. Establishing the most effective strengthening mechanism would provide theoretical guidance for improving the yield strength of austenite manganese steel. Considering the various of strengthening mechanisms, the yield strength of steels could be described as:

$$
\sigma_{\mathrm{y}}=\sigma_{0}+\sigma_{\mathrm{g}}+\sigma_{\mathrm{s}}+\sigma_{\mathrm{d}}+\sigma_{\mathrm{p}}+\sigma_{\mathrm{ss}}+\sigma_{\mathrm{t}}+\sigma_{\mathrm{sa}}
$$

where $\sigma_{0}$ was the Peierls friction of $215 \mathrm{MPa}, \sigma_{\mathrm{g}}$ was the grain boundaries, $\sigma_{\mathrm{s}}$ was the solid-solution, $\sigma_{\mathrm{d}}$ was the forest dislocation, and $\sigma_{\mathrm{p}}, \sigma_{\mathrm{ss}}, \sigma_{\mathrm{t}}, \sigma_{\mathrm{sa}}$ were the strengthening contributions associated with precipitation strengthening, substructure, texture, and strain ageing, respectively [29].

Strengthening mechanisms could be simplified by combining the heat-treatment process and microstructure observation of experimental steel. The yield strength equaled the sum of grain boundary strengthening, precipitation strengthening, and solid-solution strengthening, and was described as:

$$
\sigma_{\mathrm{y}}=\sigma_{\mathrm{g}}+\sigma_{\mathrm{p}}+\sigma_{\mathrm{ss}}
$$


The grain size effect was described by the Hall-Petch equation:

$$
\sigma_{\mathrm{g}}=\mathrm{K} d^{-1 / 2}
$$

where $\mathrm{K}$ was a constant of $11.3 \mathrm{MPa} \cdot \mathrm{mm}^{1 / 2}$ [30], $d$ was the mean austenite grain size, and the value of $d$ in CHP steel and SHPP steel was $272.46 \mu \mathrm{m}$ and $241.3 \mu \mathrm{m}$, respectively, as shown in Figure 10c. The results of $\sigma_{\mathrm{g}}$ for the two steels from Equation (3) were 21.7 MPa and 23.2 MPa, respectively, and the difference between the two $\sigma_{\mathrm{g}}$ was negligible.

The precipitation strengthening effect $\sigma_{\mathrm{p}}$ could be described by the Ashby-Orowan equation as follows [29]:

$$
\sigma_{\mathrm{p}}=9.549 \times 10^{3}\left(f^{1 / 2} / d\right) \ln (20.417 d)
$$

where $d$ was the precipitation particles' size and $f$ the precipitate volume fraction. In fact, most precipitates were micron- and submicron-sized $\mathrm{Ti}-\mathrm{Nb}$ composite precipitates, and the number of nano-sized VC was lower. Therefore, $\sigma_{\mathrm{p}}$ was calculated when the $d$ of the precipitates was taken to be $5.19 \mu \mathrm{m}$ and $7.14 \mu \mathrm{m}$, as shown in Figure 12c,d. The $f$ of the two steels' precipitates was calculated by color metallographic statistics, with that of CHP steel being about $1.2 \%$ and that of SHPP steel about $2.3 \%$. Including $f$ and $d$ in Equation (4) yielded an $\sigma_{\mathrm{p}}$ of $24.12 \mathrm{MPa}$ and $23.32 \mathrm{MPa}$, respectively, and the difference between the two $\sigma_{p}$ values was negligible.

According to the grain size result of the EBSD orientation decomposition image map, as shown in Figure 10c, there was little difference in grain size between the two steels. Meanwhile, the grain boundary strengthening effect in austenitic steel was not as obvious as in ferritic steel [31]. Therefore, although the grain size of SHPP steel was lower than that of CHP steel, the increment of grain boundary strengthening was not large. Although the average size of the precipitates in CHP steel was larger than in SHPP steel, as shown in Figure 12c,d, the volume fraction of precipitates in CHP steel was much larger than in SHPP steel. Therefore, the final computation of $\sigma_{\mathrm{p}}$ was approximate.

Compared with traditional ZGMn13Cr2, the yield strength increment of the two steels exceeded $100 \mathrm{MPa}$ [4], and the initial surface hardness also increased. According to the results of the previous calculations, the grain boundaries and precipitation strengthening contributed a strengthening increment of about $50 \mathrm{MPa}$; meanwhile, because there was no deformation process in either of the steels, the increase in dislocation strengthening could be ignored. Meanwhile, compared with the cast high-manganese steel samples, the amount and size of precipitates in the tested steels were significantly reduced through heat treatment. This caused part of the alloying elements to dissolve into the steel, resulting in a solid-solution strengthening effect in high-manganese steel. Based on the previous analysis, the residual strength increment was mainly due to solid-solution strengthening. A large number of alloying elements were added into the steel, resulting in an intensive solid-solution strengthening effect in both steels; meanwhile, the precipitation of the alloying elements only accounted for a small part of the alloy addition amount. Therefore, most of the alloying elements were still dissolved in the austenite matrix, resulting in severe lattice distortion of the crystal lattice, which improved the strength and hardness of the steel [25]. The volume fraction of precipitates in CHP steel was obviously higher than in SHPP steel, as shown in Figure 10b; therefore, the precipitation of precipitates consumed the content of alloying elements and $C$ in steel, thus weakening the replacement solid-solution strengthening of alloying elements and gap solid-solution strengthening of $\mathrm{C}$ in $\mathrm{CHP}$ steel. At the same time, according to the previous conclusion, coarse precipitates would accelerate fracture and reduce the tensile strength of steel. Therefore, the yield and tensile strengths of CHP steel decreased by $68 \mathrm{MPa}$ and $60 \mathrm{MPa}$, respectively. In this work, the precipitate particle size was too large, which was the main reason for the weak effect of precipitation strengthening.

\section{Conclusions}

The microstructure and mechanical properties of Ti-V-Nb-alloyed austenite manganese steel were investigated and the following main conclusions can be drawn: 
(1) Through the CHP and SHPP, the larger-size particles of alloying element precipitates in cast high-manganese steel were dissolved into the steel, which resulted in a significant solid-solution strengthening effect.

(2) In the SHPP, more precipitates of alloying elements could be dissolved into the steel to produce a stronger solid-solution strengthening effect and refine the austenite grain, which could increase the yield strength and maintain an excellent toughness of the steel. Finally, the impact toughness and yield strength of the SHPP steel increased by $28.3 \mathrm{~J}$ and $68 \mathrm{MPa}$, respectively.

(3) The size and volume fraction of the precipitates in CHP steel were larger than in SHPP steel, which made the surface hardness of the CHP steel higher than that of SHPP steel, but also reduced the tensile strength of CHP steel.

(4) The strengthening mechanism in both steels was mainly solid-solution strengthening, precipitation strengthening, and grain boundary strengthening. Solid-solution strengthening was the most effective strength mechanism in both steels.

(5) Adding two isothermal processes $\left(450^{\circ} \mathrm{C}\right.$ and $\left.650^{\circ} \mathrm{C}\right)$ in the heat-treatment could refine the austenite grain. Through the SHPP, Ti-V-Nb-alloyed austenite manganese steel could be an excellent material to manufacture parts requiring high strength and excellent toughness.

Author Contributions: The experiments were designed by Z.Z. (Zaifeng Zhou), Z.L., Y.J., and Q.S., and carried out by Z.Z. (Zaifeng Zhou), Z.Z. (Zhexuan Zhang), and R.G. The steels were fabricated by Z.Z. (Zaifeng Zhou), Z.Z. (Zhexuan Zhang), and R.G. The characterization tests were performed by Z.Z. (Zaifeng Zhou) and Q.S. The manuscript was written by Z.Z. (Zaifeng Zhou) and Q.S.

Funding: This work was funded by National Key R\&D Program of China (2017YFB0304700, 2017YFB0304701) and National Natural Science Foundation of China (51561018 and 51871116).

Conflicts of Interest: The authors declare no conflict of interest.

\section{References}

1. Wen, Y.H.; Peng, H.; Si, H.; Xiong, R.; Raabe, D. A novel high manganese austenitic steel with higher work hardening capacity and much lower impact deformation than Hadfield manganese steel. Mater. Des. 2014, 55, 798-804. [CrossRef]

2. Samek, L.; Arenholz, E.; Gentil, J. Extended tensile ductility of a formable high-performance high-manganese steel. Berg-und Hüttenmännische Monatshefte 2012, 157, 187-193. [CrossRef]

3. Behjati, P.; Kermanpur, A.; Najafizadeh, A.; Baghbadorani, H.S.; Jung, J.-G.; Lee, Y.-K. Enhanced mechanical properties in a high-manganese austenitic steel through formation of nano grains, nanotwinned austenite grains, nano carbides and trip. Mater. Sci. Eng. A 2014, 610, 273-278. [CrossRef]

4. Ba, Q.; Song, R.; Feng, Y.; Li, L. Microstructural Properties and Hardening Mechanism of Explosion Hardening of $\mathrm{Mn}_{13} \mathrm{Cr}_{2}$ Steel Surface. In Proceedings of the Advances in Materials Processing, Yinchuan, China, 6-12 July 2017.

5. Royston, D. Semi-autogenous grinding (SAG) mill liner design and development. Miner. Metall. Process. 2007, 23, 121-132. [CrossRef]

6. He, Z.-M.; Jiang, Q.-C.; Fu, S.-B.; Xie, J.-P. Improved work-hardening ability and wear resistance of austenitic manganese steel under non-severe impact-loading conditions. Wear 1987, 120, 305-319. [CrossRef]

7. Reyes-Calderón, F.; Mejía, I.; Boulaajaj, A.; Cabrera, J.M. Effect of microalloying elements (Nb, V and Ti) on the hot flow behavior of high-Mn austenitic twinning induced plasticity (TWIP) steel. Mater. Sci. Eng. A 2013, 560, 552-560. [CrossRef]

8. Barbangelo, A. Influence of alloying elements and heat treatment on impact toughness of chromium steel surface deposits. J. Mater. Sci. 1990, 25, 2975-2984. [CrossRef]

9. Peng, Z.; Li, L.; Gao, J.; Huo, X. Precipitation strengthening of titanium microalloyed high-strength steel plates with isothermal treatment. Mater. Sci. Eng. A 2016, 657, 413-421. [CrossRef]

10. Chen, C.Y.; Yen, H.W.; Kao, F.H.; Li, W.C.; Huang, C.Y.; Yang, J.R.; Wang, S.H. Precipitation hardening of high-strength low-alloy steels by nanometer-sized carbides. Mater. Sci. Eng. A 2009, 499, 162-166. [CrossRef] 
11. Kan, W.H.; Proust, G.; Bhatia, V.; Chang, L.; Dolman, K.; Lucey, T.; Tang, X.; Cairney, J. Slurry erosion, sliding wear and corrosion behavior of martensitic stainless steel composites reinforced in-situ with $\mathrm{NbC}$ particles. Wear 2019, 420-421, 149-162. [CrossRef]

12. Scott, C.; Remy, B.; Collet, J.-L.; Cael, A.; Bao, C.; Danoix, F.; Malard, B.; Curfs, C. Precipitation strengthening in high manganese austenitic TWIP steels. Int. J. Mater. Res. 2011, 102, 538-549. [CrossRef]

13. Smith, R.W.; Demonte, A.; Mackay, W.B.F. Development of high-manganese steels for heavy duty cast-to-shape applications. J. Mater. Process. Technol. 2004, 153-154, 589-595. [CrossRef]

14. Grajcar, A.; Borek, W. Thermo-mechanical processing of high-manganese austenitic TWIP-type steels. Arch. Civ. Mech. Eng. 2008, 8, 29-38. [CrossRef]

15. Grajcar, A.; Kciuk, M.; Topolska, S.; Płachcińska, A. Microstructure and corrosion behavior of hot-deformed and cold-strained high-Mn steels. J. Mater. Eng. Perform. 2016, 25, 2245-2254. [CrossRef]

16. De Moor, E.; Matlock, D.K.; Speer, J.G.; Merwin, M.J. Austenite stabilization through manganese enrichment. Scr. Mater. 2011, 64, 185-188. [CrossRef]

17. Cai, Z.H.; Ding, H.; Misra, R.D.K.; Ying, Z.Y. Austenite stability and deformation behavior in a cold-rolled transformation-induced plasticity steel with medium manganese content. Acta Mater. 2015, 84, $229-236$. [CrossRef]

18. Jang, J.; Heo, Y.; Lee, C.; Bhadeshia, H.; Suh, D.-W. Interphase precipitation in Ti-Nb and Ti-Nb-Mo bearing steel. Mater. Sci. Technol. 2013, 29, 309-313. [CrossRef]

19. Sourmail, T. Precipitation in creep resistant austenitic stainless steels. Mater. Sci. Technol. 2001, 17, 1-14. [CrossRef]

20. Tao, X.; Gu, J.; Han, L. Carbonitride dissolution and austenite grain growth in a high Cr ferritic heat-resistant steel. ISIJ Int. 2014, 54, 1705-1714. [CrossRef]

21. Korkut, I.; Kasap, M.; Ciftci, I.; Seker, U. Determination of optimum cutting parameters during machining of AISI 304 austenitic stainless steel. Mater. Des. 2004, 25, 303-305. [CrossRef]

22. Huang, Y.; Cheng, G.-G.; Li, S.-J.; Dai, W.-X.; Xie, Y. Effect of Ti(C, N) particle on the impact toughness of B-microalloyed steel. Metals 2018, 8, 868. [CrossRef]

23. Xu, H.F.; Zhao, J.; Cao, W.Q.; Shi, J.; Wang, C.Y.; Li, J.; Dong, H. Tempering effects on the stability of retained austenite and mechanical properties in a medium manganese steel. ISIJ Int. 2012, 52, 868-873. [CrossRef]

24. Yong, Q.L. Secondary Phases in Steels, 1st ed.; Metallurgy Industry Press: Beijing, China, 2006.

25. Zhang, X.; Godfrey, A.; Huang, X.; Hansen, N.; Liu, Q. Microstructure and strengthening mechanisms in cold-drawn pearlitic steel wire. Acta Mater. 2011, 59, 3422-3430. [CrossRef]

26. Zhang, Y.J.; Miyamoto, G.; Shinbo, K.; Furuhara, T.; Ohmura, T.; Suzuki, T.; Tsuzaki, K. Effects of transformation temperature on VC interphase precipitation and resultant hardness in low-carbon steels. Acta Mater. 2015, 84, 375-384. [CrossRef]

27. Miyamoto, G.; Hori, R.; Poorganji, B.; Furuhara, T. Interphase precipitation of VC and resultant hardening in V-added medium carbon steels. ISIJ Int. 2011, 51, 1733-1739. [CrossRef]

28. Huang, L.; Deng, X.; Jia, Y.; Li, C.; Wang, Z. Effects of using (Ti, Mo)C particles to reduce the three-body abrasive wear of a low alloy steel. Wear 2018, 410-411, 119-126. [CrossRef]

29. Wang, X.J.; Sun, X.J.; Song, C.; Chen, H.; Han, W.; Pan, F. Enhancement of yield strength by chromium/nitrogen alloying in high-manganese cryogenic steel. Mater. Sci. Eng. A 2017, 698, 110-116. [CrossRef]

30. Cuevas, F.D.L.; Reis, M.; Ferraiuolo, A.; Pratolongo, G.; Karjalainen, L.P.; Alkorta, J.; Sevillano, J.G. Hall-petch relationship of a twip steel. Key Eng. Mater. 2010, 423, 147-152. [CrossRef]

31. Bouaziz, O.; Allain, S.; Scott, C. Effect of grain and twin boundaries on the hardening mechanisms of twinning-induced plasticity steels. Scr. Mater. 2008, 58, 484-487. [CrossRef]

(C) 2019 by the authors. Licensee MDPI, Basel, Switzerland. This article is an open access article distributed under the terms and conditions of the Creative Commons Attribution (CC BY) license (http://creativecommons.org/licenses/by/4.0/). 